\title{
Quadruplet Pregnancy
}

National Cancer Institute

\section{Source}

National Cancer Institute. Quadruplet Pregnancy. NCI Thesaurus. Code C111959.

A pregnancy involving four fetuses. 